\title{
Valuation Of The Embedded Option In A Non-Cancelable Lease: Theory And Application
}

James R. Hamill, (Email: Hamill@mgt.unm.edu), University of New Mexico Joel Sternberg, (Email: JSternberg@Clarku.edu), Clark University

Craig G. White, (Email: white@mgt.unm.edu), University of New Mexico

\begin{abstract}
This paper applies a "real" option literature based model to valuing the option element of a noncancelable lease without an early exercise provision. The model is applied to a common lease typethe closed-end automobile lease. The findings show that the value of the option inherent in an automobile lease is approximately two to six percent of the original asset cost. The analysis discusses ways in which the option value can be captured through the lease contract terms. Management decision makers can use these concepts in evaluating lease/purchase decisions.
\end{abstract}

\section{INTRODUCTION}

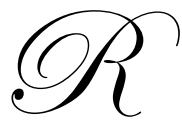

eal option theory posits that a discounted cash flow analysis is inadequate for capital budgeting purposes when the choices entail different degrees of ongoing management flexibility (Dixit and Pindyck 1994, Trigeorgis 1996). Any inherent flexibility in the use of an asset has a value separate from the expected cash flows. Many researchers identify a lease as a transaction type containing an embedded option and resulting flexibility to the lessee (Kenyon and Tompaidis 2001, Trigeorgis 1996, Grenadier 1995).

The purpose of this paper is to assist decision makers in making more robust lease versus purchase decisions through the development and illustration of a model encompassing real option principles. This criterion can be added to other decision relevant factors, such as, relative after-tax discounted cash flows and financial reporting concerns in choosing between a lease and a purchase (Copeland and Weston 1988).

The analysis in this paper utilizes the commonly encountered automobile lease versus purchase decision to illustrate application of the model. The findings show that within certain parameters of initial price, depreciation, and residual value variability, the additional value of the option inherent in an automobile lease is approximately two to six percent of the original asset cost. The results also demonstrate that the initial relative option value is negatively related to the expected depreciation rate of the asset. The analysis provides examples of the terms of a negotiated lease contract necessary to encompass the option value through the capitalized cost, interest rate, and/or the residual value.

The remainder of the discussion is organized in the following manner. The first section presents the background to real option theory and its application to an automobile lease. The second portion develops a model that is applicable to a variety of lease versus purchase decisions. The third section quantifies model parameters in the context of the automobile lease-purchase decision. Finally, the paper provides some future research directions and conclusions.

\section{BACKGROUND}

A lease is simply the purchase of the use of an asset over a specified period of time (Grenadier 1995). Leases can be negotiated providing for a wide variety of rights to the contracting parties. These rights provide differing opportunities for flexibility to the lessee and are key to the valuation of the option portion of the contract. For 
instance, a lease may contain a combination of provisions such as allowing a lessee a cancellation right and/or a purchase option for a set price at the end of the lease term (Trigeorgis 1996, Copeland and Weston 1988). This form of lease agreement has two embedded options: 1) an American put option exercisable at any time (the cancellation provision), and 2) a European call option exercisable at the end of the lease term (the purchase option) (Trigeorgis 1996). In this example, the lessee is purchasing two rights in addition to the use of the asset. If the value of the use of the asset by the lessee declines during the lease term, the lessee can cancel the lease with no further outlays. Similarly, the lessee is afforded flexibility at the end of the lease term. If the value of the asset is greater than the option purchase price, the lessee will exercise the option; otherwise, the lessee can merely return the asset.

The above example illustrates the care that must be taken in valuing the option portion of a contract. The value of these two options is not strictly addictive to the value of the use of the asset. The exercise of the first option (cancellation of the lease) "kills" the second option (the lease-end purchase option). Therefore, with multiple embedded options the analysis is complicated by the need to assess the probability of each outcome in a stepwise fashion (Trigeorgis 1996).

To illustrate the application of the model developed in this paper using available data, we focus on a common lease agreement that primarily contains a purchase option, the closed-end automobile lease. The basic automobile lease payment is made up of a depreciation component and a rent charge for the use of the vehicle. A common monthly automobile lease payment includes the following components: 1$)$ Monthly Depreciation $=($ Capitalized Cost - Residual Value) / Months in Lease Term, 2) Monthly Rent Charge $=($ Capitalized Cost + Residual Value $) \times$ Money Factor, and 3) Monthly Payment = Monthly Depreciation + Monthly Rent Charge.

The capitalized cost is the agreed upon value of the vehicle plus any amounts paid over the lease term (such as service contracts, insurance, and any outstanding prior credit or lease balance) less any net trade-in allowance, rebate, non-cash credit, or cash paid to reduce the capitalized cost. The residual value is the amount set as the contractual value of the vehicle at the end of the lease term. The money factor is an annual percentage rate (APR) divided by 24 . The money factor is merely a means for applying the monthly APR to the average value of the vehicle financed over the lease term. As discussed in detail below, this payment calculation does not take into account the option value if the parameters are the same as an outright purchase.

The option comes at the end of the lease term. The lessee has the option of purchasing the vehicle for the residual value or returning it to the lessor. In effect, the lessor retains the risk of the market value of the vehicle dropping below the residual value. As a simple example, assume the lessee leased an SUV with an original cost of $\$ 40,000$ and a residual value of $\$ 18,000$. If the vehicle is worth $\$ 20,000$ to the lessee at the end of the lease term, the lessee will pay the residual value and retain the vehicle (or possibly pay the $\$ 18,000$ and sell the vehicle). Conversely, if the vehicle depreciates to $\$ 14,000$ the lessee will return the vehicle to the lessor. The lessee has retained the upside potential, while transferring any downside to the lessor. The next section utilizes a Black/Scholes (1973) approach to value this lease-end option.

\section{VALUATION OF THE OPTION ELEMENT}

A comprehensive evaluation, including the real option component, of the advantages and disadvantages of the decision to lease rather than purchase requires an analysis utilizing derivatives. In order to accomplish this, the lease contract must be broken down into its component parts. The standard lease constitutes a monthly payment stream over a finite life. At the end of the lease life, the lessee has the option to purchase the depreciated asset at a predetermined residual value, or return it to the lessor.

The substance of the lessee's position is a long physical position in the asset, offset by a short forward position in the same asset which calls for delivery at the end of the lease. A short forward contract specifies a predetermined price and date at which an asset will be sold and delivered, in this case, back to the lessor. However, since the lessee can choose (or not) to purchase the asset at the contractual residual value at lease end, it also offers an implicit embedded call option. That call option allows the lessee to pay the contractual residual value in order to keep the asset at lease end. 
Mathematically, the lease therefore represents,

$\mathrm{S}-\mathrm{Fe}^{-\mathrm{rt}}+\mathrm{C}(\mathrm{S}, \mathrm{X}, \mathrm{t}, \mathrm{r}, \sigma)$,

where S represents the spot price of the physical asset, $-\mathrm{F}$ represents the sale of the forward contract on the asset at the contractual residual value, and $\mathrm{C}$ represents a call option on the physical asset, the value of which is a function of the spot price of the asset $(\mathrm{S})$, the strike price (equal to the forward price, $\mathrm{X}$ ), the time to the end of the lease (t), the interest rate $(\mathrm{r})$, and the volatility of the asset $(\sigma)$.

The decision to purchase the asset is represented by S, the purchase price. To find the difference in valuation between the lease and buy decision, we need only subtract one from the other, which yields,

$-\mathrm{Fe}^{-\mathrm{rt}}+\mathrm{C}$,

the present value of the contractual residual value plus the value of the call option.

Put-call parity on forward contracts dictates the following:

$\mathrm{Fe}^{-\mathrm{rt}}=\mathrm{C}-\mathrm{P}+\mathrm{Xe} \mathrm{e}^{-\mathrm{rt}}$,

where $\mathrm{Fe}^{-\mathrm{rt}}$ is the discounted price of the forward contact paid/received at delivery, $\mathrm{P}$ is a put option, and $\mathrm{Xe}^{-\mathrm{rt}}$ is the discounted value of the strike price of the put and call paid upon exercise.

The put-call parity equation applies to a European option, which unlike its American counterpart does not permit exercise prior to the expiration of the option. This methodology is applicable to the automobile lease, in which a decision on whether to purchase the asset at its residual contractual value is ultimately determined at the end of the lease.

The put-call parity equation can be rearranged for comparison with the prior equations:

$\mathrm{P}-\mathrm{Xe} \mathrm{e}^{-\mathrm{rt}}=\mathrm{C}-\mathrm{Fe}^{-\mathrm{rt}}$.

This reformulation demonstrates that the advantage of the lease "position" is that it effectively grants the lessee, in addition to the physical asset, a put option and a loan for the discounted value of the strike price. In other words, the lessee receives the value of the use of the vehicle and the lessor, effectively, loans the entire value of the asset to the lessee. Thus, a lease payment includes a depreciation portion and a "rent" charge on the value of the asset. At lease end, if the lessee no longer wishes to keep the asset, he simply exercises the put by returning the asset to the lessor. No money need change hands, since the strike price received from exercise by the lessee implicitly retires the loan due to the lessor in the same amount.

Recombining this expression with the physical asset gives

$\mathrm{S}+\mathrm{P}-\mathrm{X} \mathrm{e}^{-\mathrm{rt}}$ or $\left(\mathrm{S}-\mathrm{Xe}^{-\mathrm{rt}}\right)+\mathrm{P}$

as the lease position, where $\left(\mathrm{S}-\mathrm{Xe}^{-\mathrm{rt}}\right)$ is the present value of the contractually specified depreciation with $\mathrm{S}$ as the effective purchase price and $\mathrm{X}$ the effective residual value per the lease agreement. However, since the lease is structured as a fixed number of equal monthly payments, this depreciated amount is paid over the life of the lease, but has the same present value.

The valuation of the put option embedded in the lease requires modification of the basic formula for put valuation derived from the Black-Scholes model (Black and Scholes 1973). Black-Scholes suggest that an American put option without a dividend is valued in the following manner: 
$\mathrm{P}=\mathrm{Xe}^{-\mathrm{rt}}\left[1-\mathrm{N}\left(\mathrm{D}_{2}\right)\right]-\mathrm{S}\left[1-\mathrm{N}\left(\mathrm{D}_{1}\right)\right]$

$\mathrm{P}=\mathrm{Xe} \mathrm{e}^{-\mathrm{rt}} \mathrm{N}\left(-\mathrm{D}_{2}\right)-\mathrm{S} \mathrm{N}\left(-\mathrm{D}_{1}\right)$

where $P, S$, and $X$ are as before, $N$ is the normal density function, $D_{1}$ is $\left[\ln (S / X)+\left(r+\sigma^{2} / 2\right) t\right] / \sigma \sqrt{ } t$ and $D_{2}=D_{1}-\sigma \sqrt{ } t$. This form of the model cannot be directly applied to the option embedded in a lease because a physical asset experiences depreciation that tends to reduce its value over time.

One way to capture this factor within the context of Black-Scholes is to model depreciation as a dividend stream. This treatment is intuitively appealing since depreciation occurs hand-in-hand with a stream of economic benefits derived from holding the asset. With a continuous dividend stream, the equation for the American put modifies to:

$\mathrm{P}=\mathrm{X} \mathrm{e}^{-\mathrm{rt}} \mathrm{N}\left(-\mathrm{D}_{2}\right)-\mathrm{Se}^{-\delta \mathrm{t}} \mathrm{N}\left(-\mathrm{D}_{1}\right)$,

where $D_{1}=\left[\ln (\mathrm{S} / \mathrm{X})+\left(\mathrm{r}-\delta+\sigma^{2} / 2\right) \mathrm{t}\right] / \sigma \sqrt{ } \mathrm{t}$.

We can define $\delta$ from the amount of contractual depreciation that occurs from when the lessee takes possession of the asset to lease end, S - X, as specified earlier. Since this amount of depreciation occurs over time t, the continuous time rate of depreciation is solved from

$\mathrm{e}^{\delta \mathrm{t}}=\mathrm{S}-\mathrm{X}$.

Taking the logarithm of both sides, we get

$\delta \mathrm{t}=\ln (\mathrm{S}-\mathrm{X})$ or $\delta=\ln (\mathrm{S}-\mathrm{X}) / \mathrm{t}$,

for the continuous time rate of depreciation. In other words, the "dividend yield" or rate of depreciation can be solved from knowing the de facto selling price and estimated residual value of the asset.

In order to value the embedded put option in the lease, the only remaining value required is an interest rate for discounting purposes, and an estimate of the standard deviation of the depreciated asset around the expected residual value. This standard deviation over the life of the lease can be annualized for purposes of the above equation by the formula, $\sigma=\sqrt{ }\left(\sigma_{\mathrm{u}}{ }^{2} / \mathrm{t}\right)$, where $\mathrm{t}$ is the number of years in the lease, and $\sigma_{\mathrm{u}}$ is the unannualized standard deviation of depreciated asset values over the life of the lease.

The underpinnings of the Black-Scholes valuation formula is an arbitrage argument involving hedging put or call options with fractional shares of the underlying asset. Therefore, the adaptation of this methodology hinges on its feasibility theoretically, if not practically, to maintain a continuous hedge between the put option and fractional amounts of the underlying asset (i.e., a depreciating asset). So long as there is a market for depreciated assets, this hedge is theoretically possible, even if practically difficult.

Option methodology has been successfully applied to many arenas in which the practical aspects of trading efficiently in the underlying asset is rather challenging. Even if a perfect hedge cannot be maintained, the methodology is not entirely undermined, merely the assumption of the interest rate used to discount future values and the determination of the "growth" rate of the asset. Since, in our application, the asset "growth" is overwhelmed by depreciation, on the surface this would not appear to be of critical concern.

The analysis highlights that the lease position is always more valuable than the purchase position, because it offers a put to the lessee. Options are not generally granted for free. Therefore, it can be assumed that the lessee is implicitly paying for the option. This transfer from lessee to lessor can be accomplished in one or a combination of the following three ways: 1) the contractual value of the asset under the lease is greater than an outright purchase price, 2) 
the contractual residual value at lease end is understated relative to the expected lease-end value, and/or 3) the implicit interest rate used to amortize the lease is higher than a purchase interest rate.

In any case, the present value of the monthly payment paid over the life of the lease will overstate the true depreciation on the asset. If the contractual residual value of the asset is sufficiently understated, the put option provides no risk protection to the lessee as the lessee is certain to purchase the car at lease end. In other words, the lower the contractual residual value the more likely the ending value will exceed the residual value, negating the value of the put option. The next section applies this model to a set of automobile lease parameter estimates.

\section{APPLICATION OF THE MODEL TO AUTOMOBILE LEASES}

This section of the analysis applies the above-derived model to actual automobile lease data in order to estimate the value of the embedded option. Although the model is robust to leases of different asset types, the availability of estimated residual values for automobiles offers an opportunity to illustrate application of the model. The data, obtained from the industry standard Automotive Lease Guide (ALG) of 2003, includes the current estimated capitalized cost and projected residual values at a variety of contract lengths. The data, listed in Table 1, are samples from the categories "luxury," "mid-line," "entry-level," and "trucks." These distinct categories are utilized to examine differences in option value across initial prices and depreciation rates.

\begin{tabular}{|c|c|c|c|c|c|c|}
\hline & \multicolumn{3}{|c|}{$\begin{array}{c}\text { Table } 1 \\
\text { Estimated Residual Values } \\
\text { At Different Lease Ends }\end{array}$} & \multirow[b]{2}{*}{ Months } & \multirow[b]{2}{*}{42} & \multirow[b]{2}{*}{48} \\
\hline & $\begin{array}{l}\text { Initial } \\
\text { MSRP }\end{array}$ & 24 & 30 & & & \\
\hline \multicolumn{7}{|l|}{ Luxury } \\
\hline BMW 330i & 41,570 & 23,575 & 22,596 & 20,300 & 19,325 & 17,225 \\
\hline Lexus GS300 & 40,960 & 23,725 & 22,750 & 20,450 & 19,557 & 17,525 \\
\hline Cadillac CTS & 36,670 & 19,000 & 18,064 & 16,075 & 15,180 & 13,400 \\
\hline Average Residual Value Percentage & & $55.62 \%$ & $53.20 \%$ & $47.67 \%$ & $45.35 \%$ & $40.39 \%$ \\
\hline \multicolumn{7}{|l|}{ Mid-line } \\
\hline Chevy Impala & 22,655 & 8,500 & 8,021 & 7,075 & 6,618 & 5,775 \\
\hline Ford Taurus & 23,035 & 7,300 & 6,811 & 5,925 & 5,485 & 4,725 \\
\hline Honda Accord & 24,160 & 14,375 & 13,751 & 12,325 & 11,691 & 10,375 \\
\hline Average Residual Value Percentage & & $43.20 \%$ & $40.92 \%$ & $36.26 \%$ & $34.06 \%$ & $29.89 \%$ \\
\hline \multicolumn{7}{|l|}{ Entry Level } \\
\hline Hyundai Accent & 12,389 & 4,900 & 4,481 & 3,800 & 3,476 & 2,950 \\
\hline Ford Focus & 15,355 & 5,125 & 4,854 & 4,300 & 4,056 & 3,575 \\
\hline Chevrolet Cavalier & 15,910 & 5,125 & 4,802 & 4,200 & 3,927 & 3,425 \\
\hline Average Residual Value Percentage & & $34.70 \%$ & $32.38 \%$ & $28.18 \%$ & $26.25 \%$ & $22.79 \%$ \\
\hline \multicolumn{7}{|l|}{ Trucks } \\
\hline Chevy C1500 & 25,605 & 10,925 & 10,390 & 9,250 & 8,948 & 8,125 \\
\hline Ford 150 & 24,735 & 9,650 & 9,103 & 8,025 & 7,699 & 6,925 \\
\hline Toyota Tundra & 24,240 & 13,775 & 13,107 & 11,675 & 11,291 & 10,250 \\
\hline Average Residual Value Percentage & & $46.06 \%$ & $43.71 \%$ & $38.82 \%$ & $37.46 \%$ & $33.92 \%$ \\
\hline & & & $\begin{array}{l}\text { ta from } \\
\text { tomotiv }\end{array}$ & $\begin{array}{l}\text { Novem } \\
\text { ease GL }\end{array}$ & Decen & 2003 \\
\hline
\end{tabular}


The $A L G$ estimates indicate that different categories of vehicles are expected to maintain the highest percentage of initial value in the following order: 1) luxury cars, 2) trucks, 3) mid-line, and 4) entry level. As detailed below, this difference in expected depreciation has an impact on the value of the embedded option.

Figure 1 details the estimated embedded option value, in dollars, for each of the vehicle categories at two different standard deviations of actual residual values around the originally expected residual value.

Figure1

Option Value at Different Standard Deviations

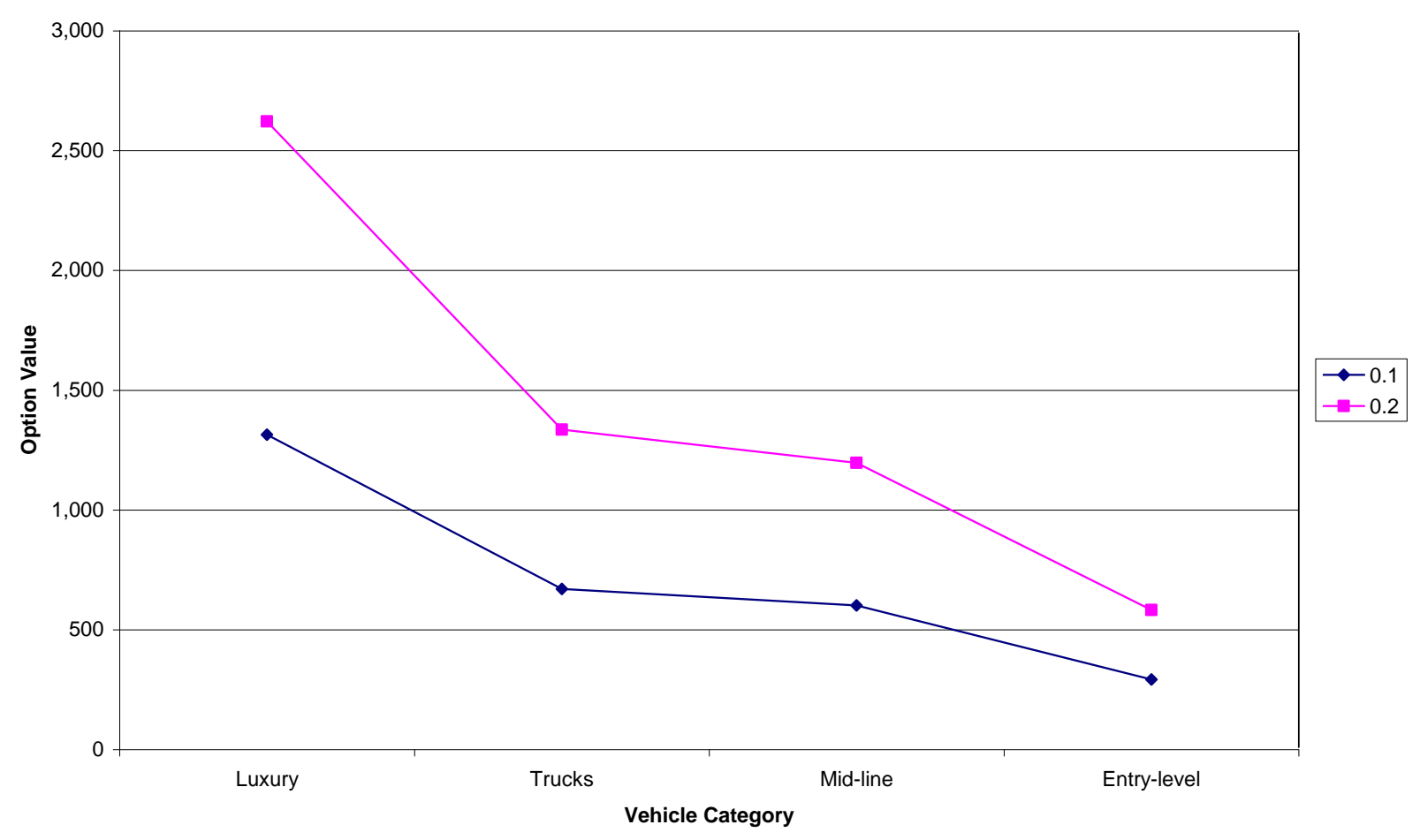

The figure utilizes a 36-month lease term and an assumed APR of 3.99 percent. The calculations are made using the following parameters based on Table 1: 1) Luxury vehicles - Manufacturer's Suggested Retail Price (MSRP) $\$ 40,000$, and residual value as a percentage of MSRP of 47.67 percent; 2) Trucks - MSRP $\$ 25,000$, and residual value as a percentage of MSRP of 38.82 percent; 3) Mid-line vehicles - MSRP \$24,000, and residual value as a percentage of MSRP of 36.26 percent; and 4) Entry-level vehicles - MSRP \$15,000, and residual value as a percentage of MSRP of 28.18 percent. The option values are calculated at two standard deviation percentages of the expected residual value, 20 percent and 10 percent.

The value of the embedded option varies in absolute dollar terms from a high of $\$ 2,622$ for the $\$ 40,000$ luxury category with a standard deviation of .2 down to a low of $\$ 292$ for the $\$ 15,000$ entry-level category with a standard deviation of .1. The figure illustrates the importance of the variability of the residual value. As with any option, a higher degree of variability of the underlying asset value results in a greater value for the embedded option. The residual value in a lease contract is a point estimate. It does not expressly take into account the possible variability of this amount. In practical terms, the value to the lessee and lessor will be based on information and prior history. 
The option value decreases as the MSRP of the vehicle decreases. The reason for this result is that the variability occurs around a lower expected residual value. The lessee and lessor have less to gain or lose on a relatively lower value. However, this finding does not reflect the relative decrease due to the smaller starting point.

Figure 2 shows the option value as a percentage of MSRP across vehicle categories and standard deviations.

Figure 2

Option Value as a Percentage of MSRP

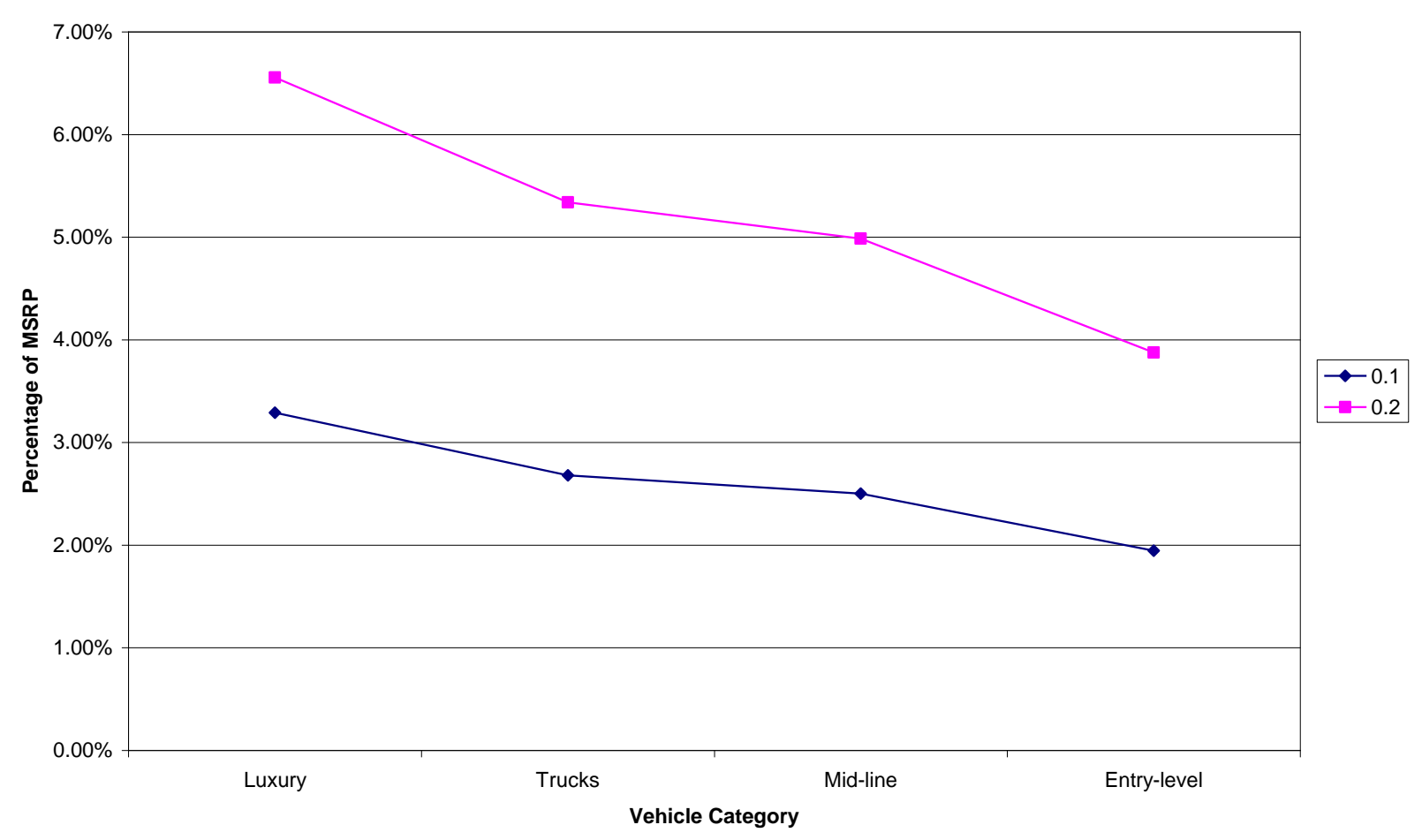

The option value ranges from a high of approximately 6.5 percent of MSRP for luxury vehicles with a 20 percent standard deviation to a low of approximately two percent for entry level vehicles with a 10 percent standard deviation. The percentage, as with the amounts in Figure 1, varies with the MSRP. However, this result is not driven by the original cost, but by the difference in depreciation rates across these vehicles. The option for luxury vehicles is worth relatively more of the MSRP due to the expected residual value representing a higher percentage of original value. Thus, the dollar amount of the variability is larger in percentage terms relative to the original cost. This reasoning can be verified by examining the ratio of option value to expected residual value. This ratio is 13.75 percent in each vehicle line. In other words, the option value, for a given standard deviation, is standardized around the expected residual value.

\section{RECOUPING THE OPTION VALUE THROUGH THE LEASE PAYMENT}

The option value can be captured through the levels of three elements of the lease contract: 1) a higher capitalized cost, 2) a lower residual value, or 3) a higher interest rate than that charged for an outright purchase. Capturing the option value through a higher capitalized cost is easily observable. This method results in an increase in capitalized cost in the amount of the option values as illustrated in Figure 1. 
A second means to compensate for the option is through setting the contractual residual value lower than the expected residual value. In effect, the lower contractual residual value reduces the risk of loss to the lessor. The lower the contractual residual value, the less likely the car will be returned to the lessor at lease end. At an extreme, if the contractual residual value were set at zero, there would little doubt that the lessee would "purchase" the car at lease end, eliminating any risk to the lessor that the car might depreciate more than anticipated. The lessee pays for more of the initial value of the vehicle than is strictly justified as the value of the asset's use. As recognized in FAS statement 13 , as the residual value decreases, the transaction begins to look more and more like an outright sale. If the true value is far greater than the residual value, the lessee has a strong incentive to exercise the purchase option.

Figure 3 illustrates the decrease in contractual residual value necessary to reduce the option value to $1, .5$, and .25 percent of the actual expected residual value for the luxury line (as opposed to the standardized 13.75 percent illustrated in Figure 2).

Figure 3

Decrease in Contractual Residual Value Necessary to Decrease Option Value to Given Percentage of Actual Expected Residual Value (Luxury Vehicle)

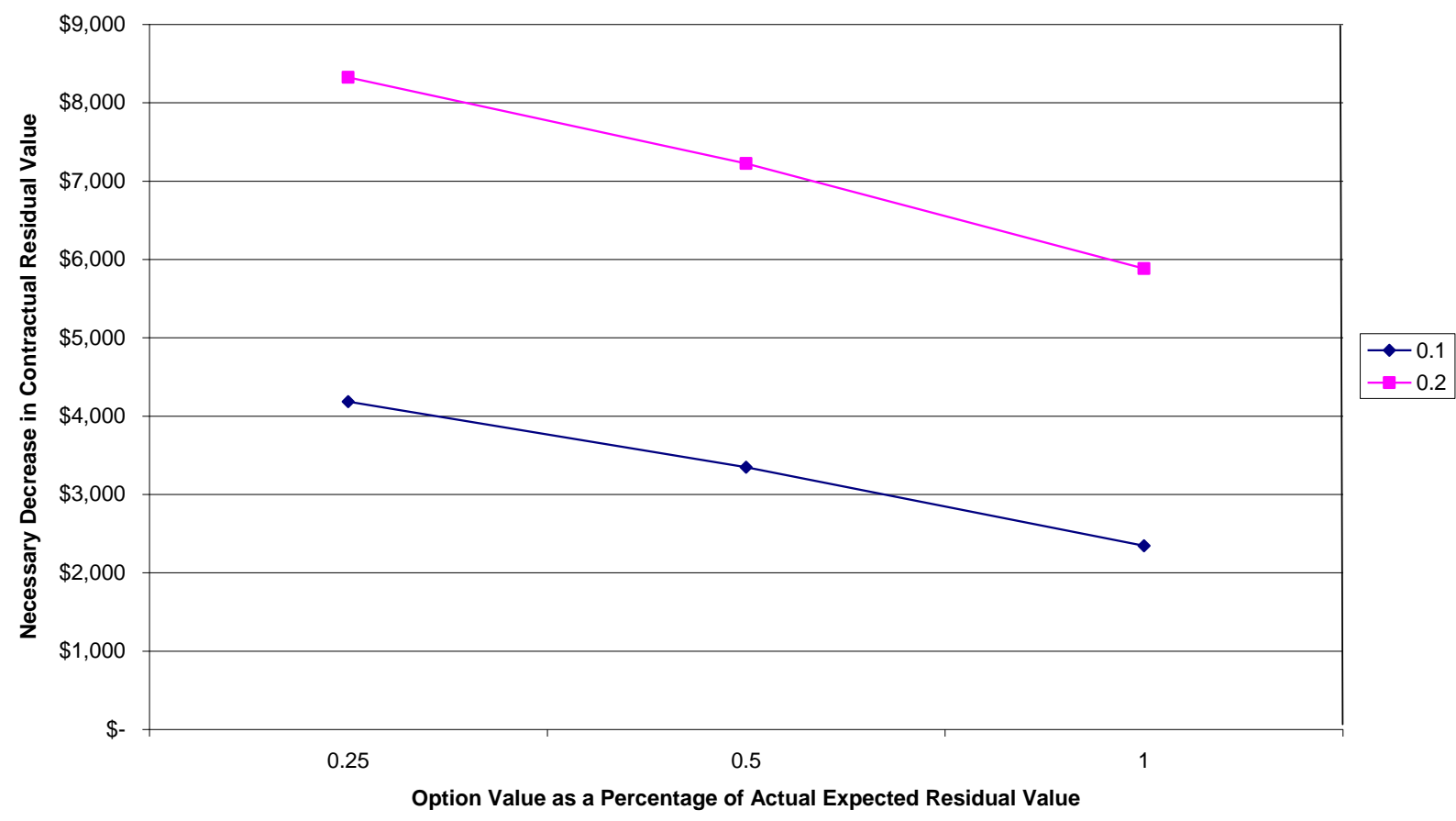

This figure illustrates that dropping the option value to insignificant levels relative to the actual expected residual value requires a large decrease in the contractual residual value. In practice, the important concept is the difference between the contractual and expected residual value.

Another possibility is for the parties to capture the option value through the interest rate. For instance, the APR could be set at the level necessary for the lease payments to yield a present value equal to the purchase price plus the option value. Under this scenario, the capitalized cost could be set at the same level as a purchase price and the contractual residual value could be set to the expected residual value, the value of the option would be accounted for via a higher APR. 
Figure 4 illustrates the increase in interest rate necessary to capture the option value given the above baseline parameters (i.e., the same MSRP, residual value, and 3.99 percent market interest rate for a purchase transaction).

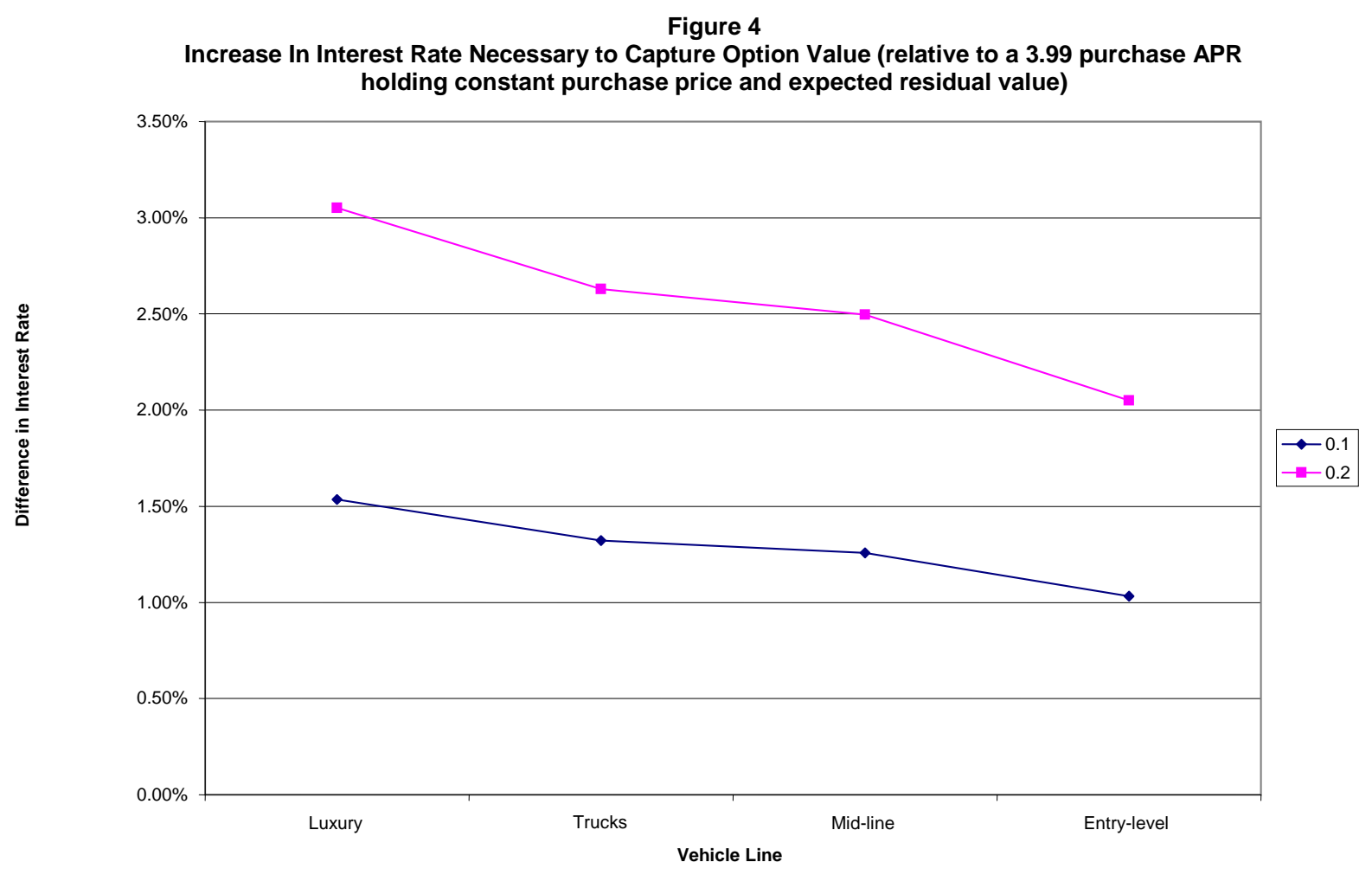

For instance, at a 20 percent standard deviation of the expected residual value, the APR on a luxury vehicle would increase to approximately seven percent to recoup the option value, given the same capitalized cost as a purchase transaction and setting the contractual residual value to that of the expected residual value. The figure demonstrates that any adjustment to the interest rate is a function of the standard deviation and the type of vehicle.

\section{RECENT AUTOMOBILE LEASE OUTCOMES}

During the late 1990s, many automobile manufacturers used leases as a way to drive volume (Truby 2000). One way to accomplish this was to set an artificially high estimated residual value. This financing decision had the effect of decreasing the monthly payment to the lessee (decreasing the depreciation charge) and increasing the value of the lessee's implicit option (by increasing the probability that the actual lease-end value would be less than the contractual residual value). Indeed, at the end of the lease term, the vehicles were often worth far less than the residual value causing a mass return of vehicles and large losses to the lessor (Truby 2000). CNW Marketing Research estimates these losses at $\$ 10.5$ billion in 2000 , with that loss based on automobiles coming off lease and sold for less than contract residual value (Fahey 2003).

Anecdotal evidence suggests that automobile lessors have become more conservative in negotiating lease terms (Truby 2000). CNW Marketing Research notes that lessors improved residual value estimates and limited the term of contracts on cars that lose resale value relatively quickly (Fahey 2003). These changes reduced estimated residual losses to $\$ 6.7$ billion in 2003 and to an estimated $\$ 4.3$ billion in 2004 (Porretto 2004). In the recent past, the lessee was often better off leasing relative to purchasing the automobile. 


\section{CONCLUSION}

The real option literature has long recognized that flexibility brings additional option value beyond the specific use of an asset. Valuation of this option value is often difficult based on potentially overlapping contractual provisions. However, the model developed in this paper provides a means to quantify the value in a common option application, the closed-end automobile lease. These concepts can be generalized to other closed-end asset lease situations.

The analysis demonstrates that there is more than one way to price the option value into a lease payment contract. Recognition of this additional option asset may sway the leasing decision even if the terms of the lease do not appear as attractive as an outright purchase.

\section{SUGGESTIONS FOR FUTURE RESEARCH}

As noted above, the model and the analysis provide insight in the analysis of actual closed-end lease situations. The model also provides a research framework for empirical studies comparing the actual contractual terms of purchases versus leases in terms of the embedded lease option. For instance, over time, are the effective selling prices of leased automobiles higher than those sold outright? Alternatively, do contractual residual values tend to be lower than projected market values at lease end? Is the interest rate higher for leases relative to outright purchases?

Another related area for exploration may involve examination of residual value insurance. For example, what does the premium for the insurance imply regarding the standard deviation of the residual value? Of course, in any future research work a key constraint will be data availability.

\section{REFERENCES}

1. Automotive Lease Guide, Manufacturer's Suggested Retail Price and Estimated Residual Values, Automotive Lease Guide, Inc., November/December, 2003.

2. Black, Fisher and Myron Scholes, The Pricing of Options and Corporate Liabilities, Journal of Political Economy; Vol. 81, pp. 637-659, 1973.

3. Copeland, Thomas and J. Fred Weston, Financial Theory and Corporate Policy, Addison-Wesley Publishing Company, Reading, MA, 1988.

4. Dixit, Avanash K. and Robert S. Pindyck, Investment Under Uncertainty. Princeton University Press, Princeton, NJ, 1994.

5. Fahey, Jonathan, Residual Risk: Auto Companies Are Stuck With Used Cars That Are Worth Less Than They thought. Bad For Them, Good For You, Forbes.Com, June 23, 2003.

6. Financial Accounting Standards Board (FASB), Accounting for Leases. FAS No. 13, FASB, Norwalk, CT, 1976.

7. Grenadier, Steven R., Valuing Lease Contracts: A Real-options Approach, Journal of Financial Economics, Vol. 38, Issue 3, pp. 297-331, 1995.

8. Kenyon, Chris and Stathis Tompaidis, Real Options in Leasing: The Effect of Idle Time, Operations Research, Vol. 49, Issue 5, pp. 675-691, 2001.

9. Poretto, John, Auto Leasing Expected to Rise in 2004, a Plus for Dealers, The Associated Press, January 31, 2004.

10. Trigeorgis, Lenos, Real Options: Managerial Flexibility and Strategy in Resource Allocation, MIT Press,Cambridge, MA, 1996.

11. Truby, Mark, Leases Slash Automaker Profits: Industry Rethinks Doling Out Sweet Deals As It Faces A Financial Hit in the Billions, The Detroit News (On-line edition); October 26, 2000. 